\title{
Chemistry of riming: the retention of organic and inorganic atmospheric trace constituents
}

\author{
Alexander Jost ${ }^{1,2}$, Miklós Szakáll ${ }^{1}$, Karoline Diehl ${ }^{1}$, Subir K. Mitra ${ }^{2}$, and Stephan Borrmann ${ }^{1,2}$ \\ ${ }^{1}$ Institute for Atmospheric Physics, University of Mainz, 55099 Mainz, Germany \\ ${ }^{2}$ Particle Chemistry Department, Max Planck Institute for Chemistry, 55218 Mainz, Germany \\ Correspondence to: Miklós Szakáll (szakall@uni-mainz.de)
}

Received: 6 March 2017 - Discussion started: 13 March 2017

Revised: 9 June 2017 - Accepted: 6 July 2017 - Published: 16 August 2017

\begin{abstract}
During free fall in clouds, ice hydrometeors such as snowflakes and ice particles grow effectively by riming, i.e., the accretion of supercooled droplets. Volatile atmospheric trace constituents dissolved in the supercooled droplets may remain in ice during freezing or may be released back to the gas phase. This process is quantified by retention coefficients. Once in the ice phase the trace constituents may be vertically redistributed by scavenging and subsequent precipitation or by evaporation of these ice hydrometeors at high altitudes. Retention coefficients of the most dominant carboxylic acids and aldehydes found in cloud water were investigated in the Mainz vertical wind tunnel under dry-growth (surface temperature less than $0^{\circ} \mathrm{C}$ ) riming conditions which are typically prevailing in the mixed-phase zone of convective clouds (i.e., temperatures from -16 to $-7{ }^{\circ} \mathrm{C}$ and a liquid water content (LWC) of $0.9 \pm 0.2 \mathrm{~g} \mathrm{~m}^{-3}$ ). The mean retention coefficients of formic and acetic acids are found to be $0.68 \pm 0.09$ and $0.63 \pm 0.19$. Oxalic and malonic acids as well as formaldehyde show mean retention coefficients of $0.97 \pm 0.06,0.98 \pm 0.08$, and $0.97 \pm 0.11$, respectively. Application of a semi-empirical model on the present and earlier wind tunnel measurements reveals that retention coefficients can be well interpreted by the effective Henry's law constant accounting for solubility and dissociation. A parameterization for the retention coefficients has been derived for substances whose aqueous-phase kinetics are fast compared to mass transport timescales. For other cases, the semi-empirical model in combination with a kinetic approach is suited to determine the retention coefficients. These may be implemented in high-resolution cloud models.
\end{abstract}

\section{Introduction}

Riming is an important process leading to the growth of glaciated hydrometeors (e.g., ice particles, snowflakes, graupel grains and hailstones) where supercooled liquid droplets collide with frozen drops or ice crystals and subsequently freeze (Pruppacher and Klett, 2010). Hence, it affects the formation of precipitation sized ice particles. During riming, soluble species present in the liquid phase could be scavenged, i.e., removed from the atmosphere by precipitation, if they remain in the ice phase during freezing. If they are not removed by precipitation, they may be carried aloft and released upon detrainment and evaporation at higher altitudes, e.g., in anvil outflows. Thus, retention during riming in the mixed-phase zone of cumulonimbus clouds and mesoscale convective systems is crucial for the vertical redistribution of trace substances. The amount of species initially dissolved in the supercooled liquid droplets that is retained in the final glaciated hydrometeor can be quantified by the so-called "retention coefficient", which assumes percentages or values between 0 and 1 . This retention is dependent on chemical properties such as solubility and dissociation (effective Henry's law constant $H^{*}$ ) but is also affected by physical factors such as droplet sizes, liquid water content (LWC), temperature, and ventilation. Ventilation characterizes the enhancement of heat and mass transfer due to flow around the collecting, falling hydrometeor. Species with high values of $H^{*}$ are expected to have $100 \%$ retention. For substances with lower values of $H^{*}$, physical factors and ambient conditions become more important (Stuart and Jacobson, 2003, 2004).

These assumptions were confirmed by wind tunnel studies of inorganic species (von Blohn et al., 2011, 2013). Hy- 
drochloric and nitric acids, both characterized by high values of $H^{*}$, were found to be fully retained in ice (von Blohn et al., 2011). For the substances with intermediate values of $H^{*}$ such as ammonia, hydrogen peroxide, and sulfur dioxide the mean retention coefficients were found to be $0.92 \pm 0.21$, $0.64 \pm 0.11$, and $0.46 \pm 0.16$, respectively (von Blohn et al., 2011, 2013). The retention coefficient of the most volatile substance, sulfur dioxide, was significantly affected by the experimental conditions (von Blohn et al., 2013). Thus, one could expect that between 50 and $100 \%$ of inorganic species stay in the ice phase during riming, which validates riming as an important process for scavenging of chemicals by the ice phase.

Water-soluble organics in the atmosphere are mainly carboxylic acids and aldehydes. Carboxylic acids are ubiquitous components of the troposphere; their primary sources are anthropogenic and biogenic emissions, and photochemical transformations of precursors (Chebbi and Carlier, 1996). These substances were detected in measurable quantities in cloud and rain water, as well as in snow samples, and even in polar ice (Chapman et al., 1986; Gunz and Hoffmann, 1990; Andreae et al., 1990; Maupetit and Delmas, 1994; Sempéré and Kawamura, 1994). The most abundant carboxylic acids found in cloud water are formic acid, acetic acid, oxalic acid, malonic acid, and succinic acid (Löflund et al., 2002; van Pinxteren et al., 2005). Especially in remote regions they are responsible for up to $65 \%$ of acidity in precipitation (Galloway et al., 1982). But also in urban regions carboxylic acids may contribute significantly to the free acidity in precipitation (Kawamura et al., 1996). Furthermore, they have a low photochemical reactivity in the atmospheric gas phase (photochemical lifetimes are more than a week), so that important sinks for these organic acids are dry and wet deposition (Chebbi and Carlier, 1996; Warneck, 2000; Warneck and Williams, 2012).

Aldehydes are related to human activities (Granby et al., 1997) and photochemistry (Riedel et al., 1999) and are involved in many atmospheric-chemistry processes. Photolysis is the main sink of formaldehyde producing $\mathrm{HO}_{\mathrm{x}}$ radicals which contribute to the oxidative capacity of the atmosphere (Cooke et al., 2010). However, as formaldehyde is soluble in water there is a pathway for redistribution by retention. Measurements of cloud water samples showed that formaldehyde is the dominant aldehyde followed by acetaldehyde and propionaldehyde (van Pinxteren et al., 2005). While in the gas phase the photolysis of formaldehyde produces $\mathrm{HO}_{\mathrm{x}}$ radicals, in the aqueous phase the reaction of $\mathrm{OH}$ with formaldehyde is one of the main sinks for this radical. In this way formaldehyde is responsible for the depletion of approximately $30 \%$ of $\mathrm{OH}$ under typical in-cloud conditions (Tilgner et al., 2013). Moreover, the reaction of formaldehyde with $\mathrm{OH}$ leads to an appreciable amount of formic acid in the aqueous phase (Adewuyi et al., 1984). Furthermore, the aqueous-phase oxidation of $\mathrm{S}(\mathrm{IV})$ to $\mathrm{S}(\mathrm{VI})$ can be in- hibited by the reaction of hydrated formaldehyde with free radicals such as $\mathrm{OH}$ (Herrmann et al., 2015).

Convective transport is an important process in the distribution of trace substances in the atmosphere since it rapidly transports atmospheric trace gases and aerosols from the boundary layer to the upper troposphere. There they have generally longer lifetimes and are more likely to undergo long-range transport (Barth et al., 2007a). Especially in the tropics, convective overshoots can lead to injection of ice particles loaded with retained trace substances even in the lowermost stratosphere (Corti et al., 2008; de Reus et al., 2009). Moreover, the shapes of hydrometeors observed in situ at high altitudes (up to $14 \mathrm{~km}$ ) often indicate the result of riming (Frey et al., 2011). For global models, the choice of the needed convection parameterization scheme has a substantial influence on trace gas distributions (Tost et al., 2010). There are some studies available in the literature which investigate the impact of deep convection on the scavenging and redistribution of trace substances in the troposphere (Mari et al., 2000; Barth et al., 2001, 2007b, a; Salzmann et al., 2007; Long et al., 2010; Leriche et al., 2013; Bela et al., 2016) but almost all emphasized the high uncertainty in their modeling studies arising from the lack of experimentally determined retention coefficients. This is especially true for watersoluble organic substances.

In contrast to inorganic substances the values for retention coefficients of organics are almost unknown. The aim of this study is to experimentally determine retention coefficients for lower carboxylic acids and aldehydes (formaldehyde) dominantly present in cloud water samples and place the obtained values into the context of those for inorganic species. Performing the experiments at the Mainz vertical wind tunnel facility allowed the simulation of conditions similar to those in mixed-phase clouds. A further aim was a comparison with previous studies on retention coefficients and to find a general parameterization for retention coefficients which can be implemented in high-resolution cloud models.

\section{Experimental}

In the present experiments, single-component systems were investigated so that the chemical properties were mainly determined by the substances themselves. This implies that possible interactions between various species present in the liquid phase are not considered (with the exception of $\mathrm{CO}_{2}$ ). As liquid water contents and droplet sizes were nearly constant, the experiments provided insights into the effects of physical factors like temperature dependency, and the influence of ventilation and different collector shapes on the retention coefficients. That is, rime collectors such as snowflakes and ice particles were floated in a vertical air flow at velocities ranging from 2 to $3 \mathrm{~m} \mathrm{~s}^{-1}$ (i.e., their terminal settling velocities inside clouds) and at typical temperatures where riming is known to be effectively leading to 
Table 1. Comparison between the experimental parameters and the ones observed in the real atmosphere. Parameter ranges and typical values (not necessarily mean values) are also given.

\begin{tabular}{lrr|rr|l}
\hline Parameter & \multicolumn{2}{c|}{ Experiment } & \multicolumn{2}{c|}{ Observed } & References \\
\cline { 2 - 5 } & Range & Typical value & Range & Typical value & \\
\hline Temperature $\left({ }^{\circ} \mathrm{C}\right)$ & -16 to -7 & -11.5 & -15 to -5 & -10 & $1,2,3$ \\
Liquid water content $(\mathrm{LWC})\left(\mathrm{g} \mathrm{m}^{-3}\right)$ & 0.5 to 1.7 & 0.9 & 0.5 to 3 & 1.0 & $3,4,5$ \\
Droplet diameter $(\mu \mathrm{m})$ & 2 to 47 & 8 & 2 to 140 & 15 & $3,5,6$ \\
Size graupel $($ diameter) $(\mathrm{mm})$ & - & 8 & 0.5 to 5 & 2 & 3,7 \\
Terminal velocity graupel $\left(\mathrm{m} \mathrm{s}^{-1}\right)$ & - & 3.0 & 0.5 to 4.0 & 1.8 & $3,7,8$ \\
Size snowflakes $($ diameter $)\left(\mathrm{mm}^{-1}\right.$ & 10 to 15 & 13 & 2 to 15 & 5 & $3,7,9,10$ \\
Terminal velocity snowflakes $\left(\mathrm{m} \mathrm{s}^{-1}\right)$ & 1.8 to 2.3 & 2.0 & 0.5 to 1.5 & 1.3 & $3,7,9,10,11$ \\
\hline
\end{tabular}

${ }^{1}$ Fukuta and Takahashi (1999); ${ }^{2}$ Long et al. (2010); ${ }^{3}$ Pruppacher and Klett (2010); ${ }^{4}$ Seinfeld and Pandis (2016); ${ }^{5}$ Warneck and Williams (2012);

${ }^{6}$ Warneck (2000); ${ }^{7}$ Locatelli and Hobbs (1974); ${ }^{8}$ Pflaum et al. (1978); ${ }^{9}$ Hanesch (1999); ${ }^{10}$ Brandes et al. (2007); ${ }^{11}$ Brandes et al. (2008)

precipitation, namely from -16 to $-7{ }^{\circ} \mathrm{C}$ (Pruppacher and Klett, 2010). Table 1 shows a comparison of the experimental parameters and the ones observed in the real atmosphere. Note that only dry-growth conditions were investigated; i.e., the surface temperatures of the rime collectors were below $0{ }^{\circ} \mathrm{C}$ during riming. The overall methodology adopted to arrive at real retention coefficients is complex and consists of many steps. Involved are (i) realistic hydrodynamical considerations, (ii) application of ion chromatography close to its detection limits, (iii) inclusion of a concentration tracking tracer, and (iv) reduction of gas-phase concentrations (see Eq. 1 for the operational mathematical expression of the retention coefficients).

\subsection{The flow conditions in the Mainz vertical wind tunnel}

In the Mainz vertical wind tunnel hydrometeors from micrometer to centimeter sizes can be freely floated at their terminal fall velocities in a vertical air stream. Therefore, ventilation (i.e., mass and heat transfer) is similar to that in the real atmosphere. Ambient air is continuously sucked through the tunnel by means of two vacuum pumps. To perform experiments in the ice phase, the tunnel air can be cooled down to $-30^{\circ} \mathrm{C}$. The air flow is laminar with a residual turbulence intensity below $0.5 \%$. More details about the wind tunnel design and experimental characteristics are given in two review papers by Szakáll et al. (2010) and Diehl et al. (2011).

\subsection{Supercooled cloud droplet characteristics}

The droplet size distribution in the wind tunnel air stream was measured by a Classical Scattering Aerosol Spectrometer Probe Electronics (CSASPE), which is a special unit designed for the wind tunnel by PMS (Particle Measurement Systems, Inc., Boulder, CO, USA). The instrument is capable of measuring the number distribution of droplets from 2 to $47 \mu \mathrm{m}$ (diameter) in 15 channels with a constant bin size of $3 \mu \mathrm{m}$. The cloud of droplets was generated in the lower

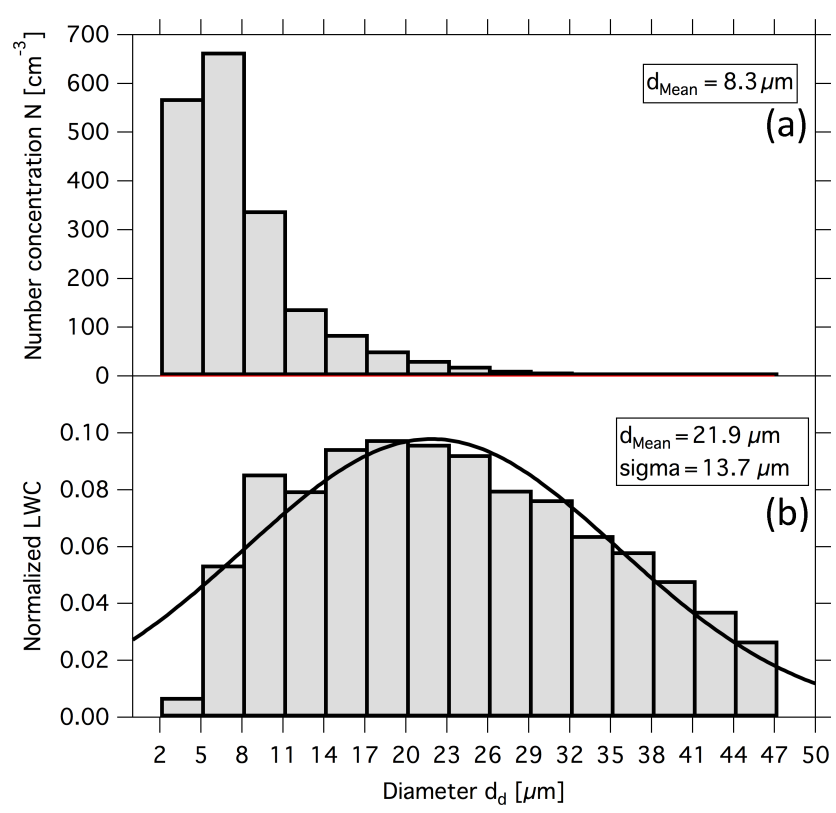

Figure 1. Droplet number (a) and mass distribution (b) of the supercooled cloud generated in the wind tunnel. The average error due to count statistics for the given distributions is $23 \%$.

part of the tunnel by two spraying nozzles (air atomizing nozzles series 1/4 J, Spraying Systems Deutschland GmbH, Hamburg, Germany) in a way such that clogging by freezing was prevented. The upper panel of Fig. 1 shows the number concentration of the supercooled cloud measured in the experimental section of the wind tunnel, where the actual retention measurements were performed (corrected for coincidence effects and dead time losses). The average error due to count statistics for each size bin was $23 \%$. The lower panel of Fig. 1 shows the mass distribution, i.e., the normalized cloud liquid water content per size interval. The mass mean diameter of the produced cloud was $22 \pm 14 \mu \mathrm{m}$. An alternative measurement for the LWC was obtained from integral measurements by means of a dew-point meter (MBW 
Table 2. Liquid-phase concentrations of the investigated substances and corresponding $\mathrm{pH}$. Ambient cloud water concentrations are means of three events (van Pinxteren et al., 2005). The presence of $\mathrm{CO}_{2}\left(\approx 400 \mu \mathrm{mol} \mathrm{mol}^{-1}\right)$ was neglected in the pH calculation except for $\mathrm{HCHO}$.

\begin{tabular}{lrrccr}
\hline Substance & $\begin{array}{r}\text { Cloud concentration } \\
\left.(\mu \mathrm{molL})^{-1}\right)\end{array}$ & $\begin{array}{r}\text { Experimental concentration } \\
\left(\mu \mathrm{molL} L^{-1}\right)\end{array}$ & $\mathrm{pH}$ & Label/purity & $\begin{array}{r}\text { Tracer concentration } \mathrm{KNO}_{3} \\
\left(\mu \mathrm{molL}^{-1}\right)\end{array}$ \\
\hline Formaldehyde & 3.1 & 100 & 5.3 & Pierce/>97\% & 30 \\
Formic acid & 65 & 4.3 & Merck/EMSURE & 30 \\
Acetic acid & 10.5 & 83 & 4.5 & Merck/EMSURE & 30 \\
Oxalic acid & 7.2 & 56 & 4.3 & Fluka/ReagentPlus & 30 \\
Malonic acid & 2.0 & 29 & 4.5 & Fluka/ReagentPlus & 30 \\
\hline
\end{tabular}

Calibration Ltd., Wettingen, Switzerland, DP3-D/SH) coupled with a $5 \mathrm{~m}$ heated pipe. The wind tunnel air containing droplets was sampled through the heated pipe isokinetically. After evaporation the dew point and, thus, the absolute humidity was determined. Afterwards, the dew point of the air without droplets was measured utilizing a droplet separator at the inlet of the heated pipe. By subtracting both absolute humidity values an average LWC of $0.9 \pm 0.2 \mathrm{~g} \mathrm{~m}^{-3}$ was obtained. The averaging refers to at least 100 measurements.

\subsection{Liquid-phase concentrations}

Table 2 summarizes the specifications of the liquid phase (i.e., the supercooled droplets) during the experiments. The second and third columns show concentrations measured in atmospheric cloud water (van Pinxteren et al., 2005) and the concentrations used in the experiments. In order to avoid analysis too close to the detection limit of the ion chromatograph (IC) the concentrations used in the experiments were approximately 1 order of magnitude higher than those found in cloud water. However, the resulting $\mathrm{pH}$ values were in a range which is typically found in cloud water, i.e., from 3.5 to 5.3 (Löflund et al., 2002). The solutions, containing a single substance, were prepared from high purity grade materials (see Table 2). Besides the trace substance of interest, potassium nitrate $\left(\mathrm{KNO}_{3}\right)$ was added as a concentration tracking tracer. Since salts are non-volatile this tracer remained completely in the ice during freezing. The tracer concentration value was used as a reference in the retention coefficient calculation to account for processes changing the concentration of the investigated substance. These processes include evaporation of the droplets and dilution of the rime ice due to the pure ice core (see Eq. 1).

\subsection{Experimental procedure}

The supercooled solution droplets containing the substance of interest and the tracer were injected into the wind tunnel upstream from the measurement section by means of two sprayer nozzles which were driven by $99.999 \% \mathrm{~N}_{2}$ gas. A specially designed drop separator was installed to avoid high ambient concentrations arising from a part of the wide beam of droplets produced by the spraying nozzles freezing on the tunnel walls. In this way, the adsorption of gas molecules of the investigated substances on the rime ice could be neglected. After a duration of approximately $8 \mathrm{~s}$, the droplets reached the measurement section of the wind tunnel, where the rime collectors were positioned. Retention is affected by the ability to transfer latent heat to the environment, which is, in turn, given by the shape of the collector and its ventilation properties (including terminal velocity). Therefore, three kinds of rime collectors were investigated: ice particles, snowflakes, and two Teflon rods (FEP). In addition, during all experiments a liquid nitrogen (LN) finger which consisted of a permanently cooled Teflon (PFA) test tube was used for the determination of the liquid-phase concentration of the droplets just before riming. The freezing on the surface of the LN finger occurred so fast that the retention value was 1 ; thus, the original concentration of the rimed droplets could be measured from the deposit by IC.

To avoid a high loss rate and contamination from contacts with the wind tunnel walls the ice particles were "captively floated", i.e., tethered on a thin nylon fiber of $80 \mu \mathrm{m}$ in diameter. In this manner they were able to move in the airstream without getting lost or contaminated and were able to properly simulate the ventilation effect. Another reason for this simplification was the size of the ice particles. For the analysis with IC and the associated minimum injection volume, it was necessary to produce a relatively large ice core when compared to atmospheric ice particles which fall at a terminal velocity of approximately $3 \mathrm{~m} \mathrm{~s}^{-1}(3-4 \mathrm{~mm}$ in diameter, Wang and Kubicek, 2013). The dimension of such a conical shaped ice particle (produced from IC-grade water) was $8 \mathrm{~mm}$ in diameter. These ice particles would actually have a much higher terminal velocity $\left(\approx 7.5 \mathrm{~m} \mathrm{~s}^{-1}\right.$; Knight and Heymsfield, 1983) especially because their density was $0.92 \mathrm{~g} \mathrm{~cm}^{-3}$. However, by suspending them it was possible to ventilate them at a typical vertical velocity of $3 \mathrm{~m} \mathrm{~s}^{-1}$.

The snowflakes were produced from dendritic ice crystals (Diehl et al., 1998; Hoog et al., 2007). Snowflakes with diameters between 10 and $15 \mathrm{~mm}$ were positioned on a coarse meshed net. To assure a negligible influence of the net on the rime process it was produced out of a thin nylon fiber with a lattice constant of approximately $8 \mathrm{~mm}$. To account for the correct ventilation, the snowflakes were "quasi-floated", 
which means that they were floated at an updraft velocity just before they were lifted from the net. In this manner the velocities were always close to the terminal velocities of the snowflakes. Due to the different sizes and slightly different bulk densities of the snowflakes the terminal velocities varied between 1.8 and $2.3 \mathrm{~m} \mathrm{~s}^{-1}$.

The FEP rods served as a reference since the rimed ice of these collectors was not diluted after melting as in the case of the ice particles and snowflakes. The FEP collectors were used to measure the retention coefficient at different ventilations. Furthermore, the retention coefficients of these collectors were used for the comparison with previous experimental and theoretical works (Stuart and Jacobson, 2003, 2004).

After a typical exposure time of $10 \mathrm{~min}$ the rimed samples were collected and the meltwater from them was analyzed with IC as described in the next subsection.

\subsection{Chemical analysis}

All five substances were analyzed by ion chromatography using a DIONEX ICS-1000 system (Dionex Corporation) in combination with the software package Chromeleon. Prior to analysis, formaldehyde was oxidized with $\mathrm{H}_{2} \mathrm{O}_{2}$ to formic acid and analyzed with the same setup as described above (Blank and Finkenbeiner, 1898; Walker, 1964). In order to validate the above method, consistency checks were performed by analyzing solutions of known concentrations.

\subsection{Calculation of the retention coefficient}

The retention coefficient was determined by the following ratio:

$R=\frac{C_{\text {substance }}^{\text {sample }} / C_{\text {tracer }}^{\text {sample }}}{C_{\text {substance }}^{\mathrm{LN}} / C_{\text {tracer }}^{\mathrm{LN}}}$

Here, the numerator describes the ratio of the concentration for the substance of interest in the ice sample $C_{\text {substance }}^{\text {sample }}$ to the tracer concentration in the ice sample $C_{\text {tracer }}^{\text {sample }}$. The denominator describes the same ratio but sampled using liquid nitrogen cooling. With this description, it is not required to account for dilution correction or evaporation correction since these effects change both the substance and the tracer concentration so that the ratio is not altered. This ratio also includes the desorption effect prior to riming since the denominator contains this loss already due to the direct measurement of the liquid-phase concentration. (The retention coefficient is 1 at such low temperatures.) Therefore, a change in this ratio is solely an effect of the retention of the substance. The error of the liquid-phase concentrations is estimated as $4.5 \%$ including the instrumental error of the IC and the error of the pipette used for producing the calibration standards for the IC. Taking these errors and applying error propagation on Eq. (1) yields a typical error for the retention coefficients of $9 \%$.

\section{Results and discussion}

Figure 2 shows the retention coefficients as a function of temperature for all investigated organic substances, namely formic acid (a), acetic acid (b), oxalic acid (c), malonic acid (d), and formaldehyde (e). The red symbols depict the rimed ice particles and the blue symbols the rimed snowflakes. Also given in Fig. 2 are the number of data points $N$ and the average retention coefficients $R$ (for formic acid and acetic acid $R$ is the value at $-11.5^{\circ} \mathrm{C}$; for the other substances it is the arithmetic mean including both collector types). The temperature of $-11.5^{\circ} \mathrm{C}$ corresponds to the mean temperature of the measurements and is specified as $T_{\mathrm{m}}$ in the next subsections. In addition to the $95 \%$ error (2SD) and the minimum/maximum values (labeled as "Min" and "Max"), the dimensionless effective Henry's law constants are shown for the $\mathrm{pH}$ of the droplets at $0{ }^{\circ} \mathrm{C}$. Note that all errors in this section correspond to 2 standard deviations (2SD). In Fig. 2a and $b$ the (dashed) red and blue curves represent linear regressions of the retention coefficients of the ice particles and snowflakes, respectively. The black lines in Fig. $2 \mathrm{a}$ are the linear regression as well as the $95 \%$ confidence bands of the whole data set, i.e., including all results for ice particles and snowflakes. The red line in panels (c), (d), and, (e) indicates a retention coefficient of 1 , or $100 \%$.

\subsection{Formic acid}

For both rime collectors, the ice particles and the snowflakes, a statistically significant negative temperature dependency (dashed lines in Fig. 2a) was found using a statistical regression test (significance level $\alpha=0.05$ ). However, when comparing the linear regressions of both collectors with the $95 \%$ confidence bands of the overall regression (solid black lines), the difference in the temperature dependencies of the retention coefficients is negligible. Therefore, the mean retention coefficient is determined by the overall regression which yields $R\left(T_{\mathrm{m}}\right)=0.68 \pm 0.09$. Finally, the retention coefficient of formic acid is only weakly dependent on temperature (when considering the error in the observed temperature range) with negligible dependencies on the shape of the collector and the ventilation conditions. The parameterization of the temperature dependency is given in Table 3 . The weak temperature dependency might be explained by the intermediate value of $H^{*}$. In this range $H^{*}$ slowly loses its dominant influence, which allows physical factors such as temperature to become more significant. There are three reasons behind the temperature dependence: first, at higher temperatures ice crystallization inside a freezing droplet proceeds slowly, which promotes the segregation process of molecules; i.e., the molecules diffuse more readily into the liquid phase and are not so effectively immobilized by the growing dendrites. This process increases the concentration in the liquid phase and drives the substance into the gas phase. According to Stuart and Jacobson (2006) this is the only factor controlling 


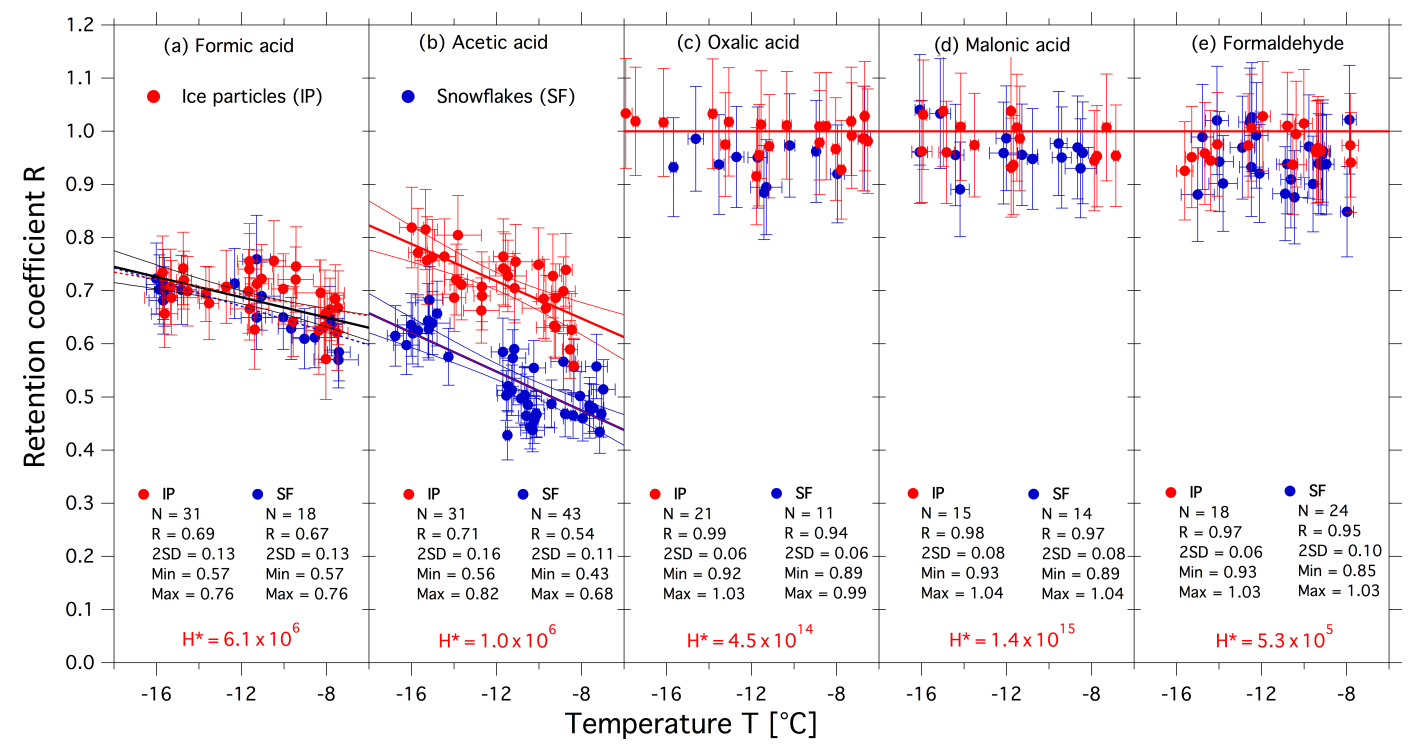

Figure 2. Retention coefficients of all measured substances as a function of temperature for different rime collectors. Red symbols: rimed ice particles. Blue symbols: rimed snowflakes. See Sect. 3 for details.

the solute transport out of the freezing droplet. Second, $H^{*}$ is lower at higher temperatures which additionally shifts the equilibrium towards the gas phase. Third, at higher temperatures the formation of an ice shell along the surface of the still supercooled liquid proceeds more slowly. Thus, the dissolved substances have more time to escape from the freezing droplet into the gas phase, which eventually reduces the retention coefficient.

\subsection{Acetic acid}

In contrast to formic acid the retention coefficients of acetic acid show a more pronounced temperature dependency. Additionally, a significant dependency of the retention coefficients on the shape of the collectors and the ventilation conditions is evident. The mean retention coefficients of the ice particles and the snowflakes at $T_{\mathrm{m}}$ are $0.72 \pm 0.16$ and $0.54 \pm 0.11$, respectively. The corresponding temperature dependencies at the $95 \%$ confidence interval of the ice particles and the snowflakes are listed in Table 3. These dependencies can be partially explained by the lower effective Henry's law constant compared to formic acid. Due to the lower $H^{*}$ the influence of temperature becomes more pronounced. Furthermore, the temperature dependency of $H^{*}$ of acetic acid is slightly higher compared to that of formic acid, which in turn increases the temperature dependency of the retention coefficient. A comparison of the ice particles and the snowflakes shows that the retention coefficient of the snowflakes is on average reduced by 0.18 . This decrease might be explained by the combination of the lower value of $H^{*}$ and a slower heat transfer process for the snowflakes compared to the ice particles which results from the reduced ventilation effect. First, the snowflakes were floated at approximately $2 \mathrm{~m} \mathrm{~s}^{-1}$, while the ice particles were floated at $3 \mathrm{~ms}^{-1}$. This difference in the settling velocities arises from the differences in size, bulk density, and shapes of the collectors. Second, the flow through the branches and around the snowflakes reduces the effective ventilation to the total exposed surface of the snowflakes. Compared to compact spheroidal ice particles this causes slower freezing times of the droplets and as a result acetic acid has more time to escape from the freezing droplets.

\subsection{Comparison of formic acid and acetic acid results}

Apparently, the retention coefficients of the snowflakes for formic acid $R\left(T_{\mathrm{m}}\right)=0.67$ and acetic acid $R\left(T_{\mathrm{m}}\right)=0.54$ differ by 0.13 . This difference can be explained by taking the mole fractions of the ionic species (formate and acetate) and molecular species (formic acid and acetic acid) into account. Besides the solubility, $H^{*}$ also depends strongly on the dissociation of a species, which, in turn, is a function of $\mathrm{pH}$. At the $\mathrm{pH}$ of the formic acid solution droplets $(\mathrm{pH}=4.3)$, only $21 \%$ of the total dissolved formic acid is present in the molecular form (calculated at $0{ }^{\circ} \mathrm{C}$ ) and the remaining $79 \%$ is in the ionic form. In contrast, at $\mathrm{pH}=4.5$ for the acetic acid droplets $64 \%$ is present in the molecular form and $36 \%$ is in the ionic form. A dissociative substance first has to recombine to the molecular form before leaving the droplet and reenter into the gas phase. Even though association (recombination) occurs quickly compared to the other timescales involved in the retention process (e.g., those of aqueousphase transport, interfacial transport, gas-phase transport of a molecule, and the freezing time), it influences the retention of acetic acid less than that of formic acid. This is because acetic acid is 3 times more present in the molecular form 
Table 3. Retention coefficients of the measured substances, their temperature dependencies, and the effect of ventilation. s.: significant; n.s.: not significant; IP: ice particles; and SF: snowflakes. Organic species: present study. Inorganic species: adopted from von Blohn et al. (2011) and von Blohn et al. (2013). HC: high concentration. LC: low concentration.

\begin{tabular}{lcll}
\hline Substance & Average $R \pm \sigma$ & Temperature dependency of $R$ & Ventilation \\
\hline Formic acid (IP+SF) & $0.68 \pm 0.05$ & $R_{\text {tot }}=(-0.010 \pm 0.002) T+(0.57 \pm 0.03)$ & n.s. \\
Acetic acid (IP) & $0.72 \pm 0.08$ & $R_{\mathrm{ip}}=(-0.018 \pm 0.004) T+(0.51 \pm 0.04)$ & $\mathrm{s}$. \\
Acetic acid (SF) & $0.54 \pm 0.06$ & $R_{\mathrm{sf}}=(-0.018 \pm 0.003) T+(0.33 \pm 0.03)$ & $\mathrm{s}$. \\
Oxalic acid (IP+SF) & $0.97 \pm 0.03$ & n.s. & n.s. \\
Malonic acid (IP+SF) & $0.98 \pm 0.04$ & n.s. & n.s. \\
Formaldehyde (IP+SF) & $0.97 \pm 0.06$ & n.s. & n.s. \\
\hline Sulfur dioxide HC (IP) & $0.35 \pm 0.08$ & $R_{\text {ip }}=(-0.025 \pm 0.003) T+(0.07 \pm 0.04)$ & s. \\
Sulfur dioxide HC (SF) & $0.22 \pm 0.05$ & $R_{\text {sf }}=(-0.016 \pm 0.002) T+(0.03 \pm 0.02)$ & s. \\
Sulfur dioxide LC (IP+SF) & $0.53 \pm 0.09$ & n.s. & n.s. \\
Hydrogen peroxide (IP+SF) & $0.64 \pm 0.14$ & n.s. & n.s. \\
Ammonia (IP+SF) & $0.92 \pm 0.21$ & n.s. & n.s. \\
Hydrochloric acid (IP+SF) & $0.99 \pm 0.03$ & n.s. & n.s. \\
Nitric acid (IP+SF) & $0.99 \pm 0.04$ & n.s. & n.s. \\
\hline
\end{tabular}

compared to formic acid which facilitates its escape to the gas phase. Furthermore, the association timescale for acetic acid is 1 order of magnitude faster than that of formic acid which further increase the degassing rate for acetic acid or on the other hand decrease that for formic acid. Moreover, an acetic acid molecule is larger (and rather linearly aligned) than a formic acid molecule which promotes the segregation of acetic acid from ice. This means that the concentration in the liquid part of the freezing droplet increases faster for acetic acid than for formic acid. This effect might lead to the formation of a concentration gradient at the liquid-gas interface forcing the acetic acid molecules to reenter the gas phase.

Comparing the mean retention coefficients $\left(R\left(T_{\mathrm{m}}\right)\right)$ of the ice particles for acetic acid and formic acid shows that they are very close to each other. Due to the stronger temperature dependency, the retention coefficients of acetic acid are slightly higher at low temperatures; however, this enhancement is within the measurement uncertainty.

\subsection{Dicarboxylic acids - oxalic and malonic acids}

Figure $2 \mathrm{c}$ and $\mathrm{d}$ represents the results of oxalic acid and malonic acid for which $H^{*}$ are almost 9 orders of magnitude higher compared to the above discussed monocarboxylic acids. This high $H^{*}$ dominates the retention process (Stuart and Jacobson, 2003), which is also reflected by the experimental results. Application of the statistical regression test on the data of oxalic acid and malonic acid reveals that the retention coefficients for both collectors do not significantly depend on temperature, and the retention coefficients can be given by their average values. The mean retention coefficients of oxalic acid for the ice particles and the snowflakes are $0.99 \pm 0.06$ and $0.94 \pm 0.06$, and between the two rime collectors there are no differences. The mean retention coef- ficients of malonic acid for the ice particles and snowflakes are $1.00 \pm 0.08$ and $0.96 \pm 0.08$, respectively. Hence, for both acids the difference between the two rime collectors is negligible. Oxalic acid and malonic acid are strong, fully dissociated acids at $\mathrm{pH}=4.3$ and $\mathrm{pH}=4.5$. This, in combination with their high intrinsic Henry's law constant results in a large $H^{*}$ that dominates all other environmental parameters influencing the retention process.

\subsection{Formaldehyde}

Formaldehyde, similarly to the dicarboxylic acids, is almost completely retained in the ice during dry-growth riming even for a relatively high concentration (see Table 2). From Fig. 2e it is obvious that the retention coefficients of the ice particles and the snowflakes are independent of temperature showing high mean retention coefficients of $0.98 \pm 0.06$ and $0.95 \pm 0.10$, respectively. As in the case of the dicarboxylic acids both values agree within the measurement error. While the retention of the dicarboxylic acids can be explained by the strong dissociation and intrinsic Henry's law constant, formaldehyde is only a weak acid with $p K_{\mathrm{a}}=13.3$ (Haynes, 2015). Also, its intrinsic Henry's law constant is low, comparable to sulfur dioxide or hydrochloric acid. However, it undergoes hydration in aqueous solutions forming methanediol (see Reaction R1) with a hydration constant of $K_{\text {hyd }}=$ $k_{\mathrm{R} 1} / k_{-\mathrm{R} 1}=1280$ (at $T=298 \mathrm{~K}$; Winkelman et al., 2002).

$$
\mathrm{CH}_{2} \mathrm{O}(\mathrm{aq})+\mathrm{H}_{2} \mathrm{O} \underset{k_{-\mathrm{R} 1}}{\stackrel{k_{\mathrm{R} 1}}{\rightleftharpoons}} \mathrm{CH}_{2}(\mathrm{OH})_{2}(\mathrm{aq})
$$

Hence, $H^{*}$ of formaldehyde does not account for the intrinsic Henry's law constant and dissociation but rather for the intrinsic Henry's law constant and hydration. Especially at low concentrations the diol form is the favored one (Walker, 1964). According to the hydration constant $K_{\text {hyd }}$ 
at $T=298 \mathrm{~K}, 99.9 \%$ of the total dissolved formaldehyde is present as methanediol, whereas less than $0.1 \%$ is present as monomeric formaldehyde. Furthermore, at such low concentrations as in the present experiments all formaldehyde and methanediol are in their monomeric forms (Walker, 1964). Nevertheless, the values of $H^{*}$ for formaldehyde are rather in an intermediate range, comparable to formic acid and acetic acid, but the retention is $100 \%$ within the measurement error. This indicates that the retention cannot be fully explained by the value of $H^{*}$, which only accounts for equilibrium conditions and gives no information on kinetic aspects. If formaldehyde gets dissolved in water its equilibrium between monomeric formaldehyde and methanediol is attained comparatively fast with a rate constant of $k_{\mathrm{R} 1}=10.7 \mathrm{~s}^{-1}$ (at $T=298 \mathrm{~K}$, Winkelman et al., 2002). However, if the equilibrium is shifted towards monomeric formaldehyde and, thus, the gas phase, methanediol first has to dehydrate with a very low rate constant $\left(k_{-\mathrm{R} 1}=8.4 \times 10^{-3} \mathrm{~s}^{-1}\right.$ at $298 \mathrm{~K}$; Winkelman et al., 2000). Presumably, the combination of both the strong hydration of formaldehyde and the low dehydration rate constant are responsible for the high retention coefficient. This means that, within the freezing time of a droplet (approximately $1 \mathrm{~ms}$ for a ventilated spread $10 \mu \mathrm{m}$ droplet), the methanediol dehydrolyzes to a very small extent. Therefore, the dissolved formaldehyde gets almost fully incorporated into the ice phase leading, to a retention coefficient close to 1 .

\section{Application of a semi-empirical model and comparison with previous works}

To the best knowledge of the authors, there are no data of retention coefficients for organics available in the literature. Therefore, the obtained values are juxtaposed with the corresponding results for inorganic species as measured in earlier studies at the Mainz wind tunnel laboratory (von Blohn et al., 2011, 2013). Two questions are to be answered in this section: (i) is $H^{*}$ the controlling parameter for both inorganic and organic substances? (ii) Can a reliable parameterization be obtained from such a comparison?

\subsection{Model description}

A meaningful tool is provided by the semi-empirical model of Stuart and Jacobson (Stuart and Jacobson, 2003, 2004) which relates the experimentally obtained retention coefficients with the so-called retention indicator (RI). This is the ratio of the expulsion timescale $\left(\tau_{\exp }\right)$ of a species from the liquid phase to the freezing time $\left(\tau_{\mathrm{frz}}\right)$ of the droplets during riming. In order to find functional dependencies of RI, first a systematic study was carried out on the influences of chemical factors on the retention process. These factors included the effective Henry's law coefficient, mass accommodation, aqueous diffusivity, and gas diffusivity as well as physical factors like temperature, droplet size and ventilation (Stuart and Jacobson, 2003). In a later study, the timescale analysis was extended to dry-growth riming accounting for spreading of the droplets' liquid onto the collector's surface and the riming conditions prevailing on a ventilated rimed rod (Stuart and Jacobson, 2004). The most relevant aspects concerning the RI are briefly summarized here (for details see Stuart and Jacobson, 2003, 2004).

The expulsion timescale $\tau_{\text {exp }}$ is the sum of characteristic timescales which are relevant for an individual substance to leave a water droplet and enter the gas phase (Schwartz, 1986). Formally the individual timescales are given as

$$
\tau_{\exp }=\underbrace{\frac{h^{2} H^{*}}{3 D_{g} \bar{f}}}_{\tau_{\mathrm{g}}}+\underbrace{\frac{4 h H^{*}}{3 \bar{v} \alpha_{m}}}_{\tau_{\mathrm{i}}}+\underbrace{\frac{h^{2}}{D_{\mathrm{aq}}}}_{\tau_{\mathrm{aq}}}+\tau_{\mathrm{r}},
$$

where $h=4 a / 3 S^{2}$ is the spread droplet height, $a$ the droplet radius, $S$ the spreading factor, $H^{*}$ the effective Henry's law coefficient, $\bar{f}$ the mean gas-phase ventilation coefficient (related to the collector's fall speed), $D_{g}$ the diffusivity of the chemical in air, $\bar{v}$ the thermal velocity of the chemical in air, $\alpha$ the mass accommodation coefficient, and $D_{\text {aq }}$ the diffusivity of the chemical in water. The first term on the righthand side of Eq. (2) describes gas-phase mass transport $\left(\tau_{\mathrm{g}}\right)$, the second term the interfacial mass transport $\left(\tau_{\mathrm{i}}\right)$ and the third term the aqueous-phase mass transport $\left(\tau_{\mathrm{aq}}\right)$. Here, a fourth timescale $\left(\tau_{\mathrm{r}}\right)$ which describes the kinetics of aqueousphase reactions (i.e., association, Seinfeld and Pandis, 2016; dehydration, Winkelman et al., 2000; or reaction with $\mathrm{CO}_{2}$, Hannemann, 1995) is added to the expulsion timescale. This timescale has been neglected in the earlier works (Stuart and Jacobson, 2003, 2004) because acid/base reactions are generally fast compared to the other processes involved. However, as shown below, it becomes important for properly determining the retention coefficients of formaldehyde and ammonia in the presence of carbon dioxide (Hannemann, 1995). The dehydration timescale results from Reaction (R1) as it is the inverse first-order rate constant $k_{-1}$ of the reverse reaction.

The total freezing time of the droplets is calculated as the sum of the adiabatic and the diabatic freezing time, viz.

$\tau_{\mathrm{frz}}=\tau_{\mathrm{ad}}+\tau_{d}$.

During adiabatic freezing no heat exchange with the environment takes place. In the associated time the dendrites penetrate through the supercooled liquid droplet and heat it up to $0{ }^{\circ} \mathrm{C}$. Note that in this time only a small fraction of the water mass is frozen depending on the supercooling of the droplets. It is assumed that shortly after this time ice shell formation is likely to occur. This would inhibit a further removal of the substance from the freezing droplet and, hence, increase the retention coefficient (Stuart and Jacobson, 2003, 2004, 2006). The diabatic freezing time is determined by the rate of latent heat removal to the underlying rime substrate 


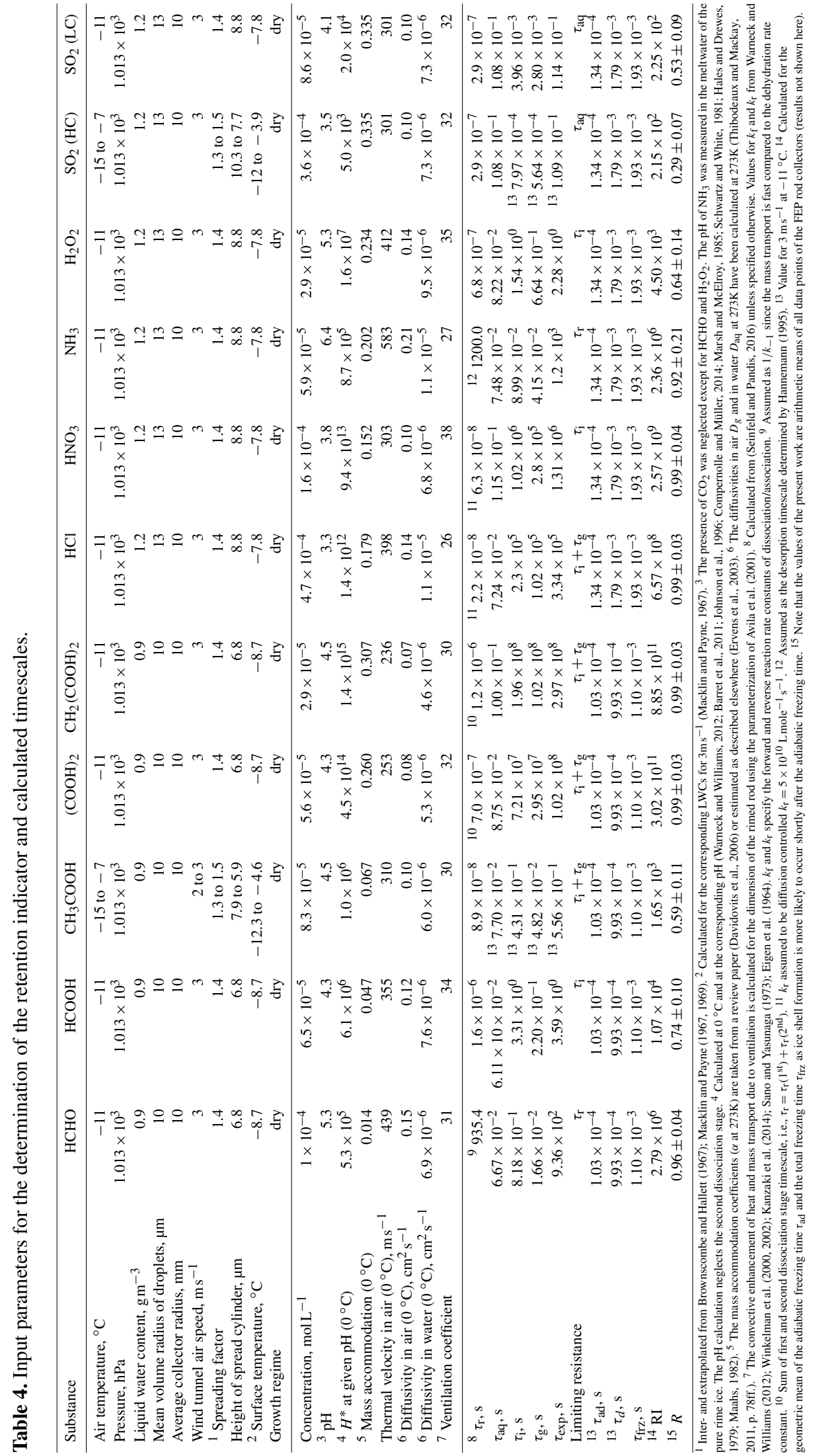




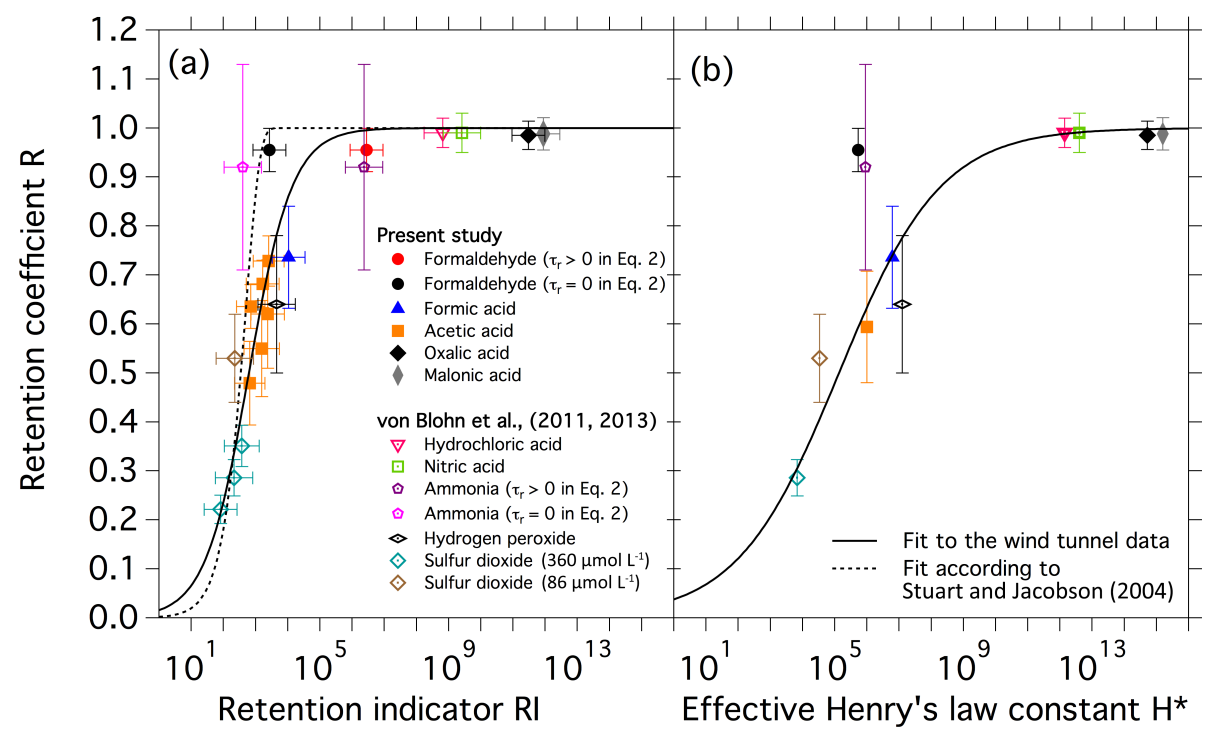

Figure 3. (a) Retention coefficient as a function of retention indicator. Filled symbols: organic substances of the present study. Open symbols: wind tunnel data from earlier studies (von Blohn et al., 2011, 2013). The black filled symbol for formaldehyde and the magenta open symbol for ammonia represent values for equilibrium conditions neglecting the aqueous-phase kinetics (see text for details). Vertical error bars are measurement uncertainties. Horizontal error bars account for the two limits of adiabatic freezing time and total freezing time of the droplets. Dotted line: fit according to Stuart and Jacobson (2004). Solid line: new fit of the wind tunnel data. (b) Retention coefficients as a function of $H^{*}$. Symbols according to (a). Solid line: new fit of the wind tunnel data. The $H^{*}$ values are calculated from literature (see Table 4) at given $\mathrm{pH}$ and at $0^{\circ} \mathrm{C}$.

and the ambient air (Stuart and Jacobson, 2004). The ventilation decreases the diabatic freezing time by increasing the heat removal to the ambient air. Due to the increased ventilation, heat transfer to air dominates that to the substrate which facilitates ice shell formation. The retention indicator is calculated as

$\mathrm{RI}=\frac{\tau_{\mathrm{exp}}}{\tau_{\mathrm{frz}}}$.

If this ratio is much higher than 1 then the substance is assumed to be fully retained in ice. If, in turn, this ratio is much lower than 1 then the substance is presumably fully expelled from the freezing droplet. Values for this ratio in an intermediate range are assumed to be directly related to the experimentally obtained retention coefficients (Stuart and Jacobson, 2003, 2004).

All necessary parameters for the calculation of the individual mass transfer timescales (Eq. 2) together with the references of the values as well as the limiting timescales, the freezing times (Eq. 3), the retention indicator (Eq. 4), and the experimentally obtained retention coefficients for all chemical substances measured in the Mainz wind tunnel laboratory are compiled in Table 4.

\subsection{Application of the model to the present and earlier wind tunnel results}

In Fig. 3a the retention coefficients of organic substances (filled symbols) investigated in the present study as well as the inorganic substances (open symbols) from earlier wind tunnel studies (von Blohn et al., 2011, 2013) are plotted as a function of the retention indicator. Note that RI was calculated as the geometric mean of the adiabatic and the total freezing time. The horizontal error bars indicate the two limits of adiabatic freezing and total freezing time of the droplets. In this way, ice shell formation is accounted for, which is assumed to be more likely to occur shortly after the adiabatic freezing time (Stuart and Jacobson, 2003, 2004, 2006). The retention coefficient of $\mathrm{SO}_{2}$ was measured for two different concentrations, one at a high value of $360 \mu \mathrm{molL}^{-1}$ (HC) and one at a low concentration of $86 \mu \mathrm{mol} \mathrm{L}^{-1}$ (LC) which has a retention coefficient of 0.53 . In the $\mathrm{HC}$ case the retention coefficient showed a significant negative temperature trend and the retention indicator as well as the retention coefficient was calculated at three different temperatures: $-7,-11$, and $-15^{\circ} \mathrm{C}$. The same was done for acetic acid, although in this case a distinction was made between the different rime collectors in order to account for the ventilation effects. The other substances did not show any significant temperature and ventilation dependencies and, hence, the retention coefficients represent average values. In these cases the retention indicators were calculated at a mean temperature of $-11^{\circ} \mathrm{C}$ and at a ventilation corresponding to $3 \mathrm{~m} \mathrm{~s}^{-1}$. The retention coefficients used in the intercomparison with the semi-empirical model were obtained from the experiments utilizing FEP rods as rime collectors. This was done because the freezing time calculations considered the 
conditions which prevailed on a previously rimed rod. Therefore, the retention coefficients differ slightly from the ones discussed in the previous section. This is especially the case for formic acid, whose retention coefficient is not temperature dependent for the FEP rods. The heat transfer for these collectors is more efficient compared to the ice particles and the snowflakes since they consisted of a stainless steel core. This caused a faster freezing of the droplets, which counteracted the weak temperature dependency of the retention coefficient for formic acid. A second result originating from the better heat transfer is that the average retention coefficient is slightly higher than in the previously presented results from Sect. 3.1. Consequently, the retention coefficient for formic acid is given as average value and not for three different temperature values. For $\mathrm{NH}_{3}$ and $\mathrm{HCHO}$, RI was calculated for two different expulsion timescales: one neglects the aqueousphase kinetics (i.e., $\tau_{\mathrm{r}}=0$ in Eq. 2) while the other one includes it (i.e., $\tau_{\mathrm{r}}>0$ in Eq. 2). This is indicated by the magenta open symbol for ammonia and the black filled symbol for formaldehyde for which the aqueous-phase kinetics are neglected. In contrast, the values represented by the purple open symbol as well as the red filled symbol include the aqueous-phase kinetics. The results for these two substances are discussed in more detail in Sect. 4.3. For the remaining substances, RI was calculated including $\tau_{\mathrm{r}}$, however, it is negligible for these substances. That is, $\tau_{\mathrm{r}}$ is several orders of magnitude smaller than the other involved timescales. The dotted line in Fig. 3a is an exponential function of the following form:

$R_{\mathrm{SJ}}=1-\exp \left(a_{5} \mathrm{RI}\right)$

where $a_{5}=-0.002 \pm 0.001, R_{\mathrm{SJ}}$ is the parameterized retention coefficient, and RI the retention indicator according to Eq. (4) (Stuart and Jacobson, 2004). However, the wind tunnel data suggest a somewhat smoother transition from low to high values. Thus, it is better represented by

$$
R_{\mathrm{RI}}=\left(1+\left(a_{6} / \mathrm{RI}\right)^{b_{6}}\right)^{-1} .
$$

Here $a_{6}=618 \pm 71$ and $b_{6}=0.64 \pm 0.06$ are fit parameters with $1 \sigma$ errors. Note that for this parameterization the values for $\mathrm{NH}_{3}$ and $\mathrm{HCHO}$ with aqueous-phase kinetics are considered. In order to quantify the accuracy of the parameterizations the average absolute error $\varepsilon$ is defined as

$\varepsilon=\frac{1}{N} \sum_{i=1}^{N}\left|R_{\mathrm{SJ}, \mathrm{RI}}^{i}-R_{\mathrm{exp}}^{i}\right|$

where $N$ is the total number of substances $i . R_{\mathrm{SJ}, \mathrm{RI}}^{i}$ are the retention coefficients applying Eq. (5) or (6) and $R_{\exp }^{i}$ are the experimentally obtained values. Utilizing Eqs. (5) and (6) on the data yields $\varepsilon=0.16$ and $\varepsilon=0.06$, respectively. Thus, the presently proposed fit function (Eq. 6) increases the accuracy by a factor of about 2.5 compared to the formerly used exponential function (Eq. 5). This improvement can be attributed to the consistency of the wind tunnel experiments as well as to the larger number of investigated substances. While Eq. (5) is based on five inorganic substances which were measured under different experimental conditions, the wind tunnel data of this study represent results of 10 organic and inorganic substances which were measured under very similar experimental conditions.

Since the retention indicator is strongly affected by the effective Henry's law constant (Stuart and Jacobson, 2003) it is worthwhile to investigate the dependency of the measured retention coefficients on $H^{*}$ (Fig. 3b). The data points represent average values of the retention coefficients of the substances. The fit curve is described by the same functional relationship as in the case of $R_{\mathrm{RI}}$ parameterization $\left(\mathrm{NH}_{3}\right.$ and $\mathrm{HCHO}$ are excluded as discussed below):

$R_{H^{*}}=\left(1+\left(a_{8} / H^{*}\right)^{b_{8}}\right)^{-1}$.

Here the fit parameters are $a_{8}=(1.69 \pm 1.05) \times 10^{5}$ and $b_{8}=$ $0.26 \pm 0.05$. From Fig. $3 b$ it is obvious that the mean retention coefficients for all investigated acids as well as for $\mathrm{H}_{2} \mathrm{O}_{2}$ regardless of whether they are inorganic or organic can be well described solely by $H^{*}$. Application of the $R_{H^{*}}$ parameterization to the acids and $\mathrm{H}_{2} \mathrm{O}_{2}$ yields a high accuracy of $\varepsilon=0.04$. The overall mass transfer timescales (Eq. 2) for the considered substances are mainly controlled by gas phase or interfacial transport (see Table 4). The presence of $\mathrm{CO}_{2}$ has a negligible effect on the mass transfer for these substances since it is only a weak acid $\left(p K_{\mathrm{a}} \approx 6.4\right)$ and does not interact with them in the aqueous phase. Even $\mathrm{H}_{2} \mathrm{O}_{2}$ is not affected by $\mathrm{CO}_{2}$ because it is more or less independent of $\mathrm{pH}$. Thus, aqueous-phase reaction kinetics are negligible for these substances. This makes the retention coefficients a strong function of $H^{*}$ as previously pointed out in the literature (Stuart and Jacobson, 2003, 2004). Furthermore, the experimental conditions of the studies concerning the inorganic substances (von Blohn et al., 2011, 2013) and the present study are very similar. Therefore, the negligible aqueous-phase kinetics and the similarity of the experiments are thought to yield such a small value of $\varepsilon$. However, while the $R_{\mathrm{RI}}$ parameterization (Fig. 3a) also accounts for ventilation, temperature, droplet size, and LWC, the $R_{H^{*}}$ parameterization (Fig. 3b) only accounts for solubility and dissociation. Nevertheless, to a first order approximation, it describes the mean of the retention coefficients quite well, especially because for most investigated substances temperature and ventilation effects are small. Consequently, the parameterization given in Eq. (8) can be applied to temperatures between -15 and $-7^{\circ} \mathrm{C}$ within the corresponding errors.

Note that the most volatile substance depicted in Fig. 3 is $\mathrm{SO}_{2}$. For even more volatile substances the influence of the physical factors might become stronger, probably increasing the error of the $R_{H^{*}}$ parameterization. However, the results of $\mathrm{SO}_{2}$ suggest that the mean of the retention values can also be 
obtained by the $R_{H^{*}}$ parameterization in such cases. While the retention coefficient of $\mathrm{SO}_{2}$ (LC) showed neither a temperature nor a collector shape (ventilation) dependency, the retention coefficient $R$ for $\mathrm{SO}_{2}$ (HC) was dependent on both parameters. Moreover, increasing the concentration from 86 to $360 \mu \mathrm{mol} \mathrm{L}^{-1}$ led to a decreasing $\mathrm{pH}$ from 4.1 to 3.5 , resulting in a smaller $H^{*}$. Even then the main part of the strong decrease in the retention coefficient from 0.53 to 0.29 could be attributed to the shift in $H^{*}$ (see Fig. 3b). Therefore, it can be surmised that also for substances which are more volatile than $\mathrm{SO}_{2}, H^{*}$ is the main factor determining the retention coefficient in the dry-growth regime. However, these results show that the retention coefficients for substances which dissociate may be affected by the $\mathrm{pH}$ of the droplets. The effective Henry's law constant $H^{*}$ combines the dissociation and the intrinsic Henry's law constant. Hence, when at least one of these constants has a high value, $H^{*}$ also becomes high making it the controlling factor for retention. In such a case the substances are more or less independent of the $\mathrm{pH}$ of the droplets because they are either fully dissociated or have a high solubility. On the other hand, if both values are low or in an intermediate range, that is, if the substances are not fully dissociated and their solubility is low, they are dependent on $\mathrm{pH}$. Experiments on the concentration dependency of the retention coefficients for $\mathrm{HCl}$ and $\mathrm{HNO}_{3}$ showed that their retentions were invariant in a pH range between 2.6 and 3.7. These two substances are fully dissociated for $\mathrm{pH}>1$, meaning that for higher $\mathrm{pH}$ values these acids are expected to show $100 \%$ retention. Furthermore, $\mathrm{HNO}_{3}$ possesses besides the high dissociation constant also a high intrinsic Henry's law constant, which suggests a retention of $100 \%$, even for a $\mathrm{pH}$ lower than 1. The same is expected for the two investigated dicarboxylic acids: oxalic acid and malonic acid for low $\mathrm{pH}$ values. These two acids have very high intrinsic Henry's law constants and moderate dissociation constants. Thus, their high retention values are mainly caused by the low volatility and not by the dissociation making their retention coefficients more or less independent of $\mathrm{pH}$. This is not the case for the monocarboxylic acids for which the intrinsic Henry's law constants as well as the dissociation constants have moderate values. Hence, the intrinsic Henry's law constant is not the dominating factor making formic acid and acetic acid more sensitively dependent on $\mathrm{pH}$, similarly to sulfur dioxide. That means, for a decreasing $\mathrm{pH}$ in the droplets, that the retentions for the monocarboxylic acids presumably decrease too and vice versa. Finally, the combined value of the equilibrium constants (i.e., $H^{*}$ ) decide to what extend the $\mathrm{pH}$ affects the retention. Therefore, the effect of the $\mathrm{pH}$ of the droplets on retention is included in the derived parameterizations as is evident from the results of $\mathrm{SO}_{2}$ as well as $\mathrm{HCl}$ and $\mathrm{HNO}_{3}$.

\subsection{Effects of aqueous-phase reactions on retention}

Conceptually, the $R_{H^{*}}$ parameterization is only valid for substances whose aqueous-phase kinetics and reactions are negligible. This is not the case for $\mathrm{NH}_{3}$ and $\mathrm{HCHO}$.

\subsubsection{Ammonia}

The solubility of $\mathrm{NH}_{3}$ is increased by several orders of magnitude in the presence of atmospheric $\mathrm{CO}_{2}$. In the wind tunnel investigations on the retention coefficient of $\mathrm{NH}_{3}$, the $\mathrm{pH}$ of the droplets was measured at consecutive times (von Blohn et al., 2013). Initially the solution had a $\mathrm{pH}$ of about 9 , which decreased approximately $2 \mathrm{~s}$ after the production of the droplets to about 8 . Finally the $\mathrm{pH}$ of the meltwater from the rimed material was 6.3. This measurement shows that the droplets absorbed $\mathrm{CO}_{2}$ in the time they were exposed in the wind tunnel $(\approx 8 \mathrm{~s})$. However, $H^{*}$ was calculated at $\mathrm{pH} 6.3$ in Fig. $3 \mathrm{~b}$ and, thus, already accounting for such an enhancement of the solubility. Nevertheless, the $R_{H^{*}}$ parameterization does not reproduce the high retention value of $\mathrm{NH}_{3}$. In Fig. 3a, the $\mathrm{RI}$ of $\mathrm{NH}_{3}(\mathrm{RI} \approx 400)$ was calculated neglecting the aqueous-phase kinetics of the $\mathrm{CO}_{2}$ reaction with $\mathrm{NH}_{3}$ (see Reactions R2 and R3 in the text below). According to the $R_{\mathrm{RI}}$ parameterization, $R$ should be about 0.4 , which is a deviation much higher than explainable by the measurement error. An experimental study (Hannemann, 1995) on the desorption of $\mathrm{NH}_{3}$ in the presence of $\mathrm{CO}_{2}$ from a water drop revealed that the desorption of $\mathrm{NH}_{3}$ is determined by two different time constants. The first one is governed by the mass transfer equivalent to $\tau_{\mathrm{aq}}+\tau_{\mathrm{i}}+\tau_{\mathrm{g}}$, which can be considered as the inverse of the overall mass transfer rate coefficient $k_{\mathrm{mt}}^{-1}$. However, in the meantime the droplet containing $\mathrm{NH}_{3}$ absorbs $\mathrm{CO}_{2}$ gradually, which reacts rapidly with $\mathrm{OH}^{-}$according to the following reaction describing the coupling of $\mathrm{NH}_{3}$ and $\mathrm{CO}_{2}$ in alkaline aqueous solution:

$$
\begin{aligned}
& \mathrm{NH}_{3}(\mathrm{aq})+\mathrm{H}_{2} \mathrm{O} \underset{k_{-\mathrm{R} 2}}{\stackrel{k_{\mathrm{R} 2}}{\rightleftharpoons}} \mathrm{NH}_{4}^{+}+\mathrm{OH}^{-}, \\
& \mathrm{CO}_{2}(\mathrm{aq})+\mathrm{OH}^{-} \underset{k_{-\mathrm{R} 3}}{\stackrel{k_{\mathrm{R} 3}}{\rightleftharpoons}} \mathrm{HCO}_{3}^{-} .
\end{aligned}
$$

Initially the system is in equilibrium according to Reaction (R2). At the very beginning when the droplets are exposed to ambient air the desorption process is determined by mass transport since the acid/base equilibrium adjusts very fast. In the presence of $\mathrm{CO}_{2}$ (at alkaline $\mathrm{pH}$ ) the reaction given by Reaction (R3) becomes important and inhibits the reverse Reaction (R2). $\mathrm{CO}_{2}$ (aq) reacts fast with $\mathrm{OH}^{-}$and forms $\mathrm{HCO}_{3}^{-}\left(k_{\mathrm{R} 3}=2.3 \times 10^{3} \mathrm{~s}^{-1}\right.$ at $6.6^{\circ} \mathrm{C}$; Wang et al., 2010). However, the reverse reaction is very slow $\left(k_{-\mathrm{R} 3}=1.4 \times 10^{-5} \mathrm{~s}^{-1}\right.$ at $6.6^{\circ} \mathrm{C}$; Wang et al., 2010) so that the opportunity of the $\mathrm{OH}^{-}$ions to recombine with $\mathrm{NH}_{4}^{+}$in order to form the volatile aqueous $\mathrm{NH}_{3}(\mathrm{aq})$ is hindered. By 
also applying a convective diffusion model including internal circulation of the liquid within the falling drop, it was shown (Hannemann, 1995) that the time to completely deplete a drop of $2.88 \mathrm{~mm}$ in radius from $\mathrm{NH}_{3}$ and to reduce $\mathrm{CO}_{2}$ back to equilibrium conditions would be $1200 \mathrm{~s}$. This timescale is taken into account in the retention indicator calculation as $\tau_{\mathrm{r}}$ (Eq. 2). Despite the large differences in the investigated drop sizes it is justified to take that value since desorption is mainly determined by the slow reverse Reaction (R3). In other words, the characteristic time of desorption in case of ammonia is controlled by chemical reaction rather than by mass transport.

\subsubsection{Formaldehyde}

A kinetic effect in the aqueous phase was also observed in the case of HCHO. The high retention coefficient in Fig. 3b cannot be explained by $H^{*}$ although hydration is included. In Fig. 3a, the RI for $\mathrm{HCHO}$ which only accounts for mass transport (i.e., $k_{\mathrm{mt}}^{-1}$ ) is given by the red open circle at $\mathrm{RI} \approx$ 3000. It is in the same range as $\mathrm{H}_{2} \mathrm{O}_{2}$ and $\mathrm{CH}_{3} \mathrm{COOH}$. However, it shows a retention coefficient of 0.96 which is well above the value predicted by the $R_{\mathrm{RI}}$ parameterization. This indicates that even mass transport effects, for example mass accommodation, cannot explain the high retention coefficient. Obviously, the overall expulsion timescale is strongly controlled by $\tau_{\mathrm{r}}$, which is the rate-limiting step in the desorption of HCHO (see Table 4). Consequently, $\tau_{\mathrm{r}}=1 / k_{-\mathrm{R} 1}=$ $935.4 \mathrm{~s}\left(k_{-\mathrm{R} 1}\right.$ extrapolated to $\left.0{ }^{\circ} \mathrm{C}\right)$ is added to the characteristic timescales for mass transport (Eq. 2). Similarly as in the case of $\mathrm{NH}_{3}$ the chemical reaction timescale $\tau_{\mathrm{r}}$ controls the desorption of $\mathrm{HCHO}$ and, therefore, retention. (Here it is not $H^{*}$ as in cases of negligible aqueous-phase kinetics.)

The two substances $\mathrm{NH}_{3}$ and $\mathrm{HCHO}$ show how aqueousphase chemical reaction kinetics could influence the retention coefficient. Particularly for such short timescales as the freezing of a $10 \mu \mathrm{m}$ ventilated spread droplet $\left(\tau_{\mathrm{frz}} \approx 10^{-3} \mathrm{~s}\right)$ the recombination/dehydration kinetics become very important for the retention process. On these short timescales this kinetic inhibition of volatilization can be viewed as an increase in solubility. For all other substances for which recombination is fast the retention can be very well described by mass transport kinetics alone, which in dry-growth conditions are predominantly determined by $H^{*}$. This might not be the case if one considers wet growth of macroscopic-sized hail where not simply one parameter dominates the retention of volatile species but rather a combination of the iceliquid interface supercooling, the LWC of the hail, and $H^{*}$ (Michael and Stuart, 2009). Hence, it is likely that physical factors determining retention such as ventilation, temperature, LWC, and droplet size become more important under wet-growth conditions and $H^{*}$ loses its dominant role.

\section{Conclusions}

Wind tunnel experiments were carried out to determine the retention coefficients of lower carboxylic acids and aldehydes during riming. Rime collectors such as snowflakes and ice particles were investigated under typical dry-growth riming conditions, i.e., temperatures from -16 to $-7^{\circ} \mathrm{C}$ and an LWC of $0.9 \pm 0.2 \mathrm{~g} \mathrm{~m}^{-3}$. By keeping the liquid water content and the droplet size distribution (mean mass diameter $22 \pm 14 \mu \mathrm{m}$ ) nearly constant during each experimental run the measurements provided information about the dependencies of the retention coefficients on ventilation effects (such as heat and mass transfer) and on ambient temperature. The retention coefficients of the measured monocarboxylic acids, formic and acetic acids, showed significant negative temperature dependencies. While the results of formic acid indicated a negligible effect on the ventilation, the results of acetic acid revealed a significant decrease in retention when comparing the ice particles (vertical velocity $w=3 \mathrm{~m} \mathrm{~s}^{-1}$ ) to the snowflakes $\left(w=2 \mathrm{~m} \mathrm{~s}^{-1}\right)$. The measured mean retention coefficients of formic acid and acetic acid were $0.68 \pm 0.09$ and $0.63 \pm 0.19$, respectively. Oxalic acid and malonic acid as well as formaldehyde showed retention coefficients of $0.97 \pm 0.06,0.98 \pm 0.08$, and $0.97 \pm 0.11$ without significant temperature and ventilation dependencies.

The application of a semi-empirical model (Stuart and Jacobson, 2004) on the present experimental results and on the previously obtained retention coefficients for inorganic substances (von Blohn et al., 2011, 2013) show that retention can be well described by the retention indicator, i.e., the ratio of the sum of kinetic mass transfer timescales to the freezing time of the droplets on the surface of the collector. For those substances for which aqueous-phase kinetics (chemical reaction or association) are fast compared to mass transport the mean values of the retention coefficients can be well interpreted using the effective Henry's law constant. The derived functional relationship of retention coefficients on the effective Henry's law constant suggests a high accuracy, which makes it a very simple estimation tool for retention coefficients, probably also for substances not investigated so far. Thus, the parameterization can be easily implemented in high-resolution cloud models which include retention in the dry-growth riming regime.

However, from the measurements with formaldehyde and ammonia it was found that retention is primarily controlled by aqueous-phase kinetic effects. The retention of formaldehyde is controlled by the dehydration of methanediol. On such short timescales as the freezing of cloud droplets this can be considered as an increase in solubility and, therefore, retention. The retention of ammonia is strongly affected by the kinetics of the reaction of $\mathrm{CO}_{2}(\mathrm{aq})$ with $\mathrm{OH}^{-}$. Both cases emphasize the importance of accounting for chemical reactions when describing retention. However, modifying the semi-empirical model (Stuart and Jacobson, 2004) by adding appropriate kinetic timescales (e.g., by adding the 
inverse of dehydration rate) makes it a well-suited tool for describing retention coefficients even for such substances for which aqueous-phase kinetics are the limiting factor. Generally, acid/base reactions are several orders of magnitude faster than mass transport processes. Nonetheless, before applying the $R_{H^{*}}$ parameterization it is recommended to first check the recombination/dehydration kinetics of the substance of interest and compare them with the mass transport timescales.

Finally, the work contributes to the improvement of highresolution cloud models which simulate the redistribution of atmospheric trace gases. For example, our experiments verify the estimation of the retention coefficients for formic acid and acetic acid applied in Leriche et al. (2013) and Bela et al. (2016). Nevertheless, they underestimated the retention coefficient values of formaldehyde. However, strictly speaking, the present work is only applicable to dry-growth conditions and one-component systems in the presence of $\mathrm{CO}_{2}$. Further experiments which account for more realistic compositions of chemicals in cloud water, for example by measuring retention coefficients of categorized mixtures (tropical, urban, rural, etc.), would give further insight into the process. Moreover, an extension to wet-growth conditions is necessary in order to quantify the retention of trace substances throughout all riming regimes in convective storms.

Data availability. Experimental data are freely available upon request to the contact author.

Author contributions. Author contributions: AJ, MS, KD, SKM, and SB designed research; AJ performed research; AJ, and SKM performed and developed the chemical analysis; AJ, MS, KD, SKM, and SB evaluated the data; AJ, MS, KD, SKM, and SB wrote the paper.

Competing interests. The authors declare that they have no conflict of interest.

Acknowledgements. This work was supported by the Deutsche Forschungsgemeinschaft under grant MI 483/6-1, as well as by internal funds from the Max Planck Institute for Chemistry.

Edited by: Jennifer G. Murphy

Reviewed by: two anonymous referees

\section{References}

Adewuyi, Y. G., Cho, S.-Y., Tsay, R.-P., and Carmichael, G. R.: Importance of formaldehyde in cloud chemistry, Atmos. Environ., 18, 2413-2420, 1984.
Andreae, M., Talbot, R., Berresheim, H., and Beecher, K.: Precipitation chemistry in central Amazonia, Dry season, J. Geophys. Res., 95, 16987-16999, 1990.

Avila, E. E., Pereyra, R. G., Castellano, N. E., and Saunders, C. P.: Ventilation coefficients for cylindrical collectors growing by riming as a function of the cloud droplet spectra, Atmos. Res., 57, 139-150, 2001.

Barret, M., Houdier, S., and Domine, F.: Thermodynamics of the Formaldehyde-Water and Formaldehyde-Ice Systems for Atmospheric Applications, J. Phys. Chem. A., 115, 307-317, 2011.

Barth, M. C., Stuart, A. L., and Skamarock, W. C.: Numerical simulations of the July 10, 1996, Stratospheric-Tropospheric Experiment: Radiation, Aerosols, and Ozone (STERAO)-Deep Convection experiment storm: Redistribution of soluble tracers, J. Geophys. Res., 106, 12381-12400, 2001.

Barth, M. C., Kim, S.-W., Skamarock, W. C., Stuart, A. L., Pickering, K. E., and Ott, L. E.: Simulations of the redistribution of formaldehyde, formic acid, and peroxides in the 10 July 1996 Stratospheric-Tropospheric Experiment: Radiation, Aerosols, and Ozone deep convection storm, J. Geophys. Res.Atmos., 112, D13310, https://doi.org/10.1029/2006JD008046, 2007a.

Barth, M. C., Kim, S.-W., Wang, C., Pickering, K. E., Ott, L. E., Stenchikov, G., Leriche, M., Cautenet, S., Pinty, J.-P., Barthe, Ch., Mari, C., Helsdon, J. H., Farley, R. D., Fridlind, A. M., Ackerman, A. S., Spiridonov, V., and Telenta, B.: Cloudscale model intercomparison of chemical constituent transport in deep convection, Atmos. Chem. Phys., 7, 4709-4731, https://doi.org/10.5194/acp-7-4709-2007, 2007b.

Bela, M. M., Barth, M. C., Toon, O. B., Fried, A., Homeyer, C. R., Morrison, H., Cummings, K. A., Li, Y., Pickering, K. E., Allen, D. J., Yang, Q., Wennberg, P. O., Crounse, J. D., St. Clair, J. M., Teng, A. P., O’Sullivan, D., Huey, L. G., Chen, D., Liu, X., Blake, D. R., Blake, N. J., Apel, E. C., Hornbrook, R. S., Flocke, F., Campos, T., and Diskin, G.: Wet scavenging of soluble gases in DC3 deep convective storms using WRF-Chem simulations and aircraft observations, J. Geophys. Res.-Atmos., 121, 4233-4257, https://doi.org/10.1002/2015JD024623, 2016.

Blank, O. and Finkenbeiner, H.: Üeber eine neue Methode zur quantitativen Bestimmung von Formaldehyd, Ber. Dtsch. Chem. Ges., 31, 2979-2981, 1898.

Brandes, E. A., Ikeda, K., Zhang, G., Schönhuber, M., and Rasmussen, R. M.: A Statistical and Physical Description of Hydrometeor Distributions in Colorado Snowstorms Using a Video Disdrometer, J. Appl. Meteorol. Clim., 46, 634-650, 2007.

Brandes, E. A., Ikeda, K., Thompson, G., and Schönhuber, M.: Aggregate Terminal Velocity/Temperature Relations, J. Appl. Meteorol. Clim., 47, 2729-2736, 2008.

Brownscombe, J. L. and Hallett, J.: Experimental and field studies of precipitation particles formed by the freezing of supercooled water, Q. J. Roy. Meteor. Soc., 93, 455-473, 1967.

Chapman, E., Sklarew, D., and Flickinger, J.: Organic acids in springtime Wisconsin precipitation samples, Atmos. Environ., 20, 1717-1725, 1986.

Chebbi, A. and Carlier, P.: Carboxylic acids in the troposphere, occurence, sources, and sinks: a review, Atmos. Environ., 30, 42334249, 1996.

Compernolle, S. and Müller, J.-F.: Henry's law constants of diacids and hydroxy polyacids: recommended values, Atmos. 
Chem. Phys., 14, 2699-2712, https://doi.org/10.5194/acp-142699-2014, 2014.

Cooke, M. C., Utembe, S. R., Carbajo, P. G., Archibald, A. T., OrrEwing, A. J., Jenkin, M. E., Derwent, R. G., Lary, D. J., and Shallcross, D. E.: Impacts of formaldehyde photolysis rates on tropospheric chemistry, Atmos. Sci. Lett., 11, 33-38, 2010.

Corti, T., Luo, B. P., de Reus, M., Brunner, D., Cairo, F., Mahoney, M. J., Martucci, G., Matthey, R., Mitev, V., dos Santos, F. H., Schiller, C., Shur, G., Sitnikov, N. M., Spelten, N., Vössing, H. J., Borrmann, S., and Peter, T.: Unprecedented evidence for deep convection hydrating the tropical stratosphere, Geophys. Res. Lett., 35, L10810, https://doi.org/10.1029/2008GL033641, 2008.

Davidovits, P., Kolb, C. E., Williams, L. R., Jayne, J. T., and Worsnop, D. R.: Mass Accommodation and Chemical Reactions at Gas/Liquid Interfaces, Chem. Rev., 106, 1323-1354, 2006.

de Reus, M., Borrmann, S., Bansemer, A., Heymsfield, A. J., Weigel, R., Schiller, C., Mitev, V., Frey, W., Kunkel, D., Kürten, A., Curtius, J., Sitnikov, N. M., Ulanovsky, A., and Ravegnani, F.: Evidence for ice particles in the tropical stratosphere from in-situ measurements, Atmos. Chem. Phys., 9, 6775-6792, https://doi.org/10.5194/acp-9-6775-2009, 2009.

Diehl, K., Mitra, S., and Pruppacher, H.: A laboratory study on the uptake of $\mathrm{HCl}, \mathrm{HNO} 3$, and $\mathrm{SO} 2$ gas by ice crystals and the effect of these gases on the evaporation rate of the crystals, Atmos. Res., 47-48, 235-244, 1998.

Diehl, K., Mitra, S. K., Szakáll, M., von Blohn, N., Borrmann, S., and Pruppacher, H. R.: The Mainz vertical wind tunnel facility: a review of 25 years of laboratory experiments on cloud physics and chemistry, in: Wind Tunnels: Aerodynamics, Models, and Experiments, edited by: Pereira, J. D., Nova Science Publishers, Inc., 2, 69-92, 2011.

Eigen, M., Kruse, W., Maass, G., and Maeyer, L. D.: Rate Constants of Protolytic Reactions in Aqueous Solution, in: Progress in Reaction Kinetics, edited by: Porter, G., Pergamon Press Ltd., 2, 285-318, 1964.

Ervens, B., George, C., Williams, J. E., Buxton, G. V., Salmon, G. A., Bydder, M., Wilkinson, F., Dentener, F., Mirabel, P., Wolke, R., and Herrmann, H.: CAPRAM 2.4 (MODAC mechanism): An extended and condensed tropospheric aqueous phase mechanism and its application, J. Geophys. Res.-Atmos., 108, 4426, https://doi.org/10.1029/2002JD002202, 2003.

Frey, W., Borrmann, S., Kunkel, D., Weigel, R., de Reus, M., Schlager, H., Roiger, A., Voigt, C., Hoor, P., Curtius, J., Krämer, M., Schiller, C., Volk, C. M., Homan, C. D., Fierli, F., Di Donfrancesco, G., Ulanovsky, A., Ravegnani, F., Sitnikov, N. M., Viciani, S., D’Amato, F., Shur, G. N., Belyaev, G. V., Law, K. S., and Cairo, F.: In situ measurements of tropical cloud properties in the West African Monsoon: upper tropospheric ice clouds, Mesoscale Convective System outflow, and subvisual cirrus, Atmos. Chem. Phys., 11, 5569-5590, https://doi.org/10.5194/acp11-5569-2011, 2011.

Fukuta, N. and Takahashi, T.: The Growth of Atmospheric Ice Crystals: A Summary of Findings in Vertical Supercooled Cloud Tunnel Studies, J. Atmos. Sci., 56, 1963-1979, 1999.

Galloway, J. N., Likens, G. E., Keene, W. C., and Miller, J. M.: The composition of precipitation in remote areas of the world, J. Geophys. Res., 87, 8771-8786, 1982.
Granby, K., Christensen, C., and Lohse, C.: Urban and semi-rural observations of carboxylic acids and carbonyls, Atmos. Environ., 31, 1403-1415, 1997.

Gunz, D. and Hoffmann, M.: Field investigation on the snow chemistry in central and southern California. II. Carbonyls and carboxyl acids, Atmos. Environ., 16, 969-981, 1990.

Hales, J. M. and Drewes, D. R.: Solubility of ammonia in water at low concentrations, Atmos. Environ., 13, 1133-1147, 1979.

Hanesch, M.: Fall velocity and Shape of Snowflakes, Ph.D. thesis, Swiss Federal Institute of Technology, 1999.

Hannemann, A.: Eine experimentelle und theoretische Untersuchung zu gekoppelten Aufnahme von $\mathrm{SO}_{2}, \mathrm{NH}_{3}$ und $\mathrm{CO}_{2}$ in Wassertropfen, Ph.D. thesis, Institute for Physics of the Atmosphere, University of Mainz, Germany, 1995.

Haynes, W. M. (Ed.): Handbook of Chemistry and Physics, CRC Press, 96 edn., 2015.

Herrmann, H., Schaefer, T., Tilgner, A., Styler, S. A., Weller, C., Teich, M., and Otto, T.: Tropospheric Aqueous-Phase Chemistry: Kinetics, Mechanisms, and Its Coupling to a Changing Gas Phase, Chem. Rev., 115, 4259-4334, 2015.

Hoog, I., Mitra, S. K., Diehl, K., and Borrmann, S.: Laboratory studies about the interaction of ammonia with ice crystals at temperatures between 0 and $20^{\circ} \mathrm{C}$, J. Atmos. Chem., 57, 73-84, 2007.

Johnson, B. J., Betterton, E. A., and Craig, D.: Henry's Law Coefficients of Formic and Acetic Acids, J. Atmos. Chem., 24, 113119, 1996.

Kanzaki, Y., Tokuda, K., and Bruckenstein, S.: Dissociation Rates of Weak Acids Using Sinusoidal Hydrodynamic Modulated Rotating Disk Electrode Employing Koutecky-Levich Equation, J. Electrochem. Soc., 161, H770-H779, 2014.

Kawamura, K., Steinberg, S., and Kaplan, I. R.: Concentrations of Monocarboxylic and Dicarboxylic Acids and Aldehydes in Southern California Wet Precipitations: Composition of Urban and Non-Urban Samples and Compositional Changes During Scavenging, Atmos. Environ., 30, 1035-1052, 1996.

Knight, N. C. and Heymsfield, A. J.: Measurement and Interpretation of Hailstone Density and Terminal Velocity, J. Atmos. Sci., 40, 1510-1516, 1983.

Leriche, M., Pinty, J.-P., Mari, C., and Gazen, D.: A cloud chemistry module for the 3-D cloud-resolving mesoscale model Meso-NH with application to idealized cases, Geosci. Model Dev., 6, 12751298, https://doi.org/10.5194/gmd-6-1275-2013, 2013.

Locatelli, J. D. and Hobbs, P. V.: Fall speeds and masses of solid precipitation particles, J. Geophys. Res., 79, 2185-2197, 1974.

Löflund, M., Kasper-Giebl, A., Schuster, B., Giebl, H., Hitzenberger, R., and Puxbaum, H.: Formic, acetic, oxalic, malonic and succinic acid concentrations and their contribution to organic carbon in cloudwater, Atmos. Environ., 36, 1553-1558, 2002.

Long, Y., Chaumerliac, N., Deguillaume, L., Leriche, M., and Champeau, F.: Effect of mixed-phase cloud on the chemical budget of trace gases: A modeling approach, Atmos. Res., 97, 540554, 2010.

Maahs, H. G.: Sulfur-dioxide/water equilibria between $0^{\circ}$ and $50^{\circ} \mathrm{C}$. An examination of data at low concentrations, in: Heterogeneous Atmospheric Chemistry, edited by: Schryer, D. R., 187-195, American Geophysical Union, 1982.

Macklin, W. C. and Payne, G. S.: A theoretical study of the ice accretion process, Q. J. Roy. Meteor. Soc., 93, 195-213, 1967. 
Macklin, W. C. and Payne, G. S.: The spreading of accreted droplets, Q. J. Roy. Meteor. Soc., 95, 724-730, 1969.

Mari, C., Jacob, D. J., and Bechtold, P.: Transport and scavenging of soluble gases in a deep convective cloud, J. Geophys. Res.Atmos., 105, 22255-22267, 2000.

Marsh, A. and McElroy, W.: The dissociation constant and Henry's law constant of $\mathrm{HCl}$ in aqueous solution, Atmos. Environ., 19, 1075-1080, 1985.

Maupetit, F. and Delmas, J.: Carboxyl acids in high-elevation glacier snow, J. Geophys. Res., 99, 16491-16500, 1994.

Michael, R. and Stuart, A. L.: The fate of volatile chemicals during wet growth of a hailstone, Environ. Res. Lett., 4, 015001, https://doi.org/10.1088/1748-9326/4/1/015001, 2009.

Pflaum, J. C., Martin, J. J., and Pruppacher, H. R.: A wind tunnel investigation of the hydrodynamic behaviour of growing freely falling graupel, Q. J. Roy. Meteor. Soc., 104, 179-187, 1978.

Pruppacher, H. R. and Klett, J. D.: Microphysics of clouds and precipitation, Springer, 2 edn., 2010.

Riedel, K., Weller, R., and Schrems, O.: Variability of formaldehyde in the Antarctic atmosphere, Phys. Chem. Chem. Phys., 1, 55235527, 1999.

Salzmann, M., Lawrence, M. G., Phillips, V. T. J., and Donner, L. J.: Model sensitivity studies regarding the role of the retention coefficient for the scavenging and redistribution of highly soluble trace gases by deep convective cloud systems, Atmos. Chem. Phys., 7, 2027-2045, https://doi.org/10.5194/acp-7-2027-2007, 2007.

Sano, T. and Yasunaga, T.: Kinetic Studies of Dissociation and Recombination Reaction in Aqueous Solutions of Dicarboxylic Acids by Means of Ultrasonic Absorption Measurements, J. Phys. Chem., 77, 2031-2038, 1973.

Schwartz, S. E.: Mass transport considerations pertinent to aqueous phase reactions of gases in liquid water clouds, in: Chemistry of Multiphase Atmospheric Systems, edited by: Jaeschke, W., vol. 6 of NATO ASI Series, Springer-Verlag Berlin Heidelberg, 415472, 1986.

Schwartz, S. E. and White, W. H.: Solubility equilibria of the nitrogen oxides and oxyacids in dilute aqueous solution, in: Advances in Environmental Sciences and Engeneering, edited by: Pfafflin, J. R. and Ziegler, E. N., Gordan and Breach Science Publishers, 4, 1-45, 1981.

Seinfeld, J. H. and Pandis, S. N.: Atmospheric Chemistry and Physics - From Air Pollution to Climate Change, John Wiley and Sons, Inc., 3 edn., 2016.

Sempéré, R. and Kawamura: Comparative distribution of carboxylic acids and related polar compounds in snow, rain, and aerosols from urban atmosphere, Atmos. Environ., 28, 449-459, 1994.

Stuart, A. and Jacobson, M.: A timescale investigation of volatile chemical retention during hydrometeor freezing: Nonrime freezing and dry growth riming without spreading, J. Geophys. Res., 108, 4178, https://doi.org/10.1029/2001JD001408, 2003.

Stuart, A. and Jacobson, M.: Chemical retention during dry growth riming, J. Geophys. Res., 109, D07305, https://doi.org/10.1029/2003JD004197, 2004.
Stuart, A. L. and Jacobson, M. Z.: A numerical model of the partitioning of trace chemical solutes during drop freezing, J. Atmos. Chem., 53, 13-42, 2006.

Szakáll, M., Diehl, K., Mitra, S. K., and Borrmann, S.: Shapes and oscillations of falling raindrops - a review, J. Atmos. Res., 97, 416-425, 2010.

Thibodeaux, L. J. and Mackay, D. (Eds.): Handbook of Chemical Mass Transport in the Environment, CRC Press, 2011.

Tilgner, A., Bräuer, P., Wolke, R., and Herrmann, H.: Modelling multiphase chemistry in deliquescent aerosols and clouds using CAPRAM3.0i, J. Atmos. Chem., 70, 221-256, 2013.

Tost, H., Lawrence, M. G., Brühl, C., Jöckel, P., The GABRIEL Team, and The SCOUT-O3-DARWIN/ACTIVE Team: Uncertainties in atmospheric chemistry modelling due to convection parameterisations and subsequent scavenging, Atmos. Chem. Phys., 10, 1931-1951, https://doi.org/10.5194/acp-101931-2010, 2010.

van Pinxteren, D., Plewka, A., Hofmann, D., Müller, K., Kramberger, H., Svrcina, B., Bächmann, K., Jaeschke, W., Mertes, S., Collett Jr., J. L., and Herrmann, H.: Schmücke hill cap cloud and valley stations aerosol characterisation during FEBUKO (II): Organic compounds, Atmos. Environ., 39, 4305-4320, 2005.

von Blohn, N., Diehl, K., Mitra, S. K., and Borrmann, S.: Wind tunnel experiments on the retention of trace gases during riming: nitric acid, hydrochloric acid, and hydrogen peroxide, Atmos. Chem. Phys., 11, 11569-11579, https://doi.org/10.5194/acp-1111569-2011, 2011.

von Blohn, N., Diehl, K., Nölscher, A., Jost, A., Mitra, S. K., and Borrmann, S.: The retention of ammonia and sulfur dioxide during riming of ice particles and dendritic snow flakes: laboratory experiments in the Mainz vertical wind tunnel, J. Atmos. Chem., 70, 131-150, 2013.

Walker, J.: Formaldehyde, American chemical society monograph series, Reinhold, 1964.

Wang, P. K. and Kubicek, A.: Flow fields of graupel falling in air, Atmos. Res., 124, 158-169, 2013.

Wang, X., Conway, W., Burns, R., McCann, N., and Maeder, M.: Comprehensive Study of the Hydration and Dehydration Reactions of Carbon Dioxide in Aqueous Solution, J. Phys. Chem. A., 114, 1734-1740, 2010.

Warneck, P.: Chemistry of the Natural Atmosphere, International geophysics series, Academic Press, 2 edn., https://books.google. co.uk/books?id=dm4RAQAAIAAJ, 2000.

Warneck, P. and Williams, J.: The Atmospheric Chemist's Companion, Springer, 2012.

Winkelman, J. G. M., Ottens, M., and Beenackers, A. A. C. M.: The kinetics of the dehydration of methylene glycol, Chemical Engeneering Science, 55, 2065-2071, 2000.

Winkelman, J. G. M., Voorwinde, O. K., Ottens, M., Beenackers, A. A. C. M., and Janssen, L. P. B. M.: Kinetics and chemical equilibrium of the hydration of formaldehyde, Chemical Engeneering Science, 57, 4067-4076, 2002. 